\title{
ESTÁGIO SUPERVISIONADO OBRIGATÓRIO EM SERVIÇO SOCIAL: UM DESAFIO PARA NOVAS METODOLOGIAS DE ENSINO NA MODALIDADE EAD.
}

\author{
MARINGÁ, PARANA, BRASIL/PR JULHO/2018
}

\begin{abstract}
Suzie Keilla Viana da Silva - UNICESUMAR - suziekeilla72@gmail.com
Aryane Leinne Oliveira Matioli - UNICESUMAR - aryane.matioli@unicesumar.edu.br

Maria Cristina Araújo de Brito Cunha - UNICESUMAR - maria.cunha@unicesumar.edu.br
\end{abstract}

Tipo: Investigação Científica (IC)

Natureza: Relatório Final de Pesquisa

Categoria: Métodos e Tecnologias

Setor Educacional: EDUCAÇÃO SUPERIOR

\begin{abstract}
RESUMO
Este artigo é resultado de estudos bibliográficos e da experiência no Curso de Bacharelado em Serviço Social da UNICESUMAR. Seu principal objetivo é o de propiciar algumas análises sobre a importância do estágio supervisionado em Serviço Social. A pesquisa priorizou demonstrar as disciplinas diferenciadas de estágio curricular obrigatório do curso de Serviço Social fazendo com que $o$ acadêmico(a) ao se confrontar com questões e impasses de sua profissão na contemporaneidade, seja capaz de uma reflexão teórico-prática na concretização de soluções frente às diferentes demandas sociais; e a capacitação disponibilizada aos Supervisores Acadêmicos, possibilitando o processo de ensino-aprendizagem na modalidade Ead do estágio, que proporciona um método educativo e introspectivo de ensino-aprendizagem.
\end{abstract}

Palavras-chave: Serviço Social; Formação Profissional; Estágio Supervisionado; Supervisão Acadêmica. 


\section{INTRODUÇÃo}

A educação tem passado por intensas transformações, e as práticas pedagógicas tem assumido novos formatos, que são direcionados principalmente pelos desafios impostos pelo uso da tecnologia no processo de ensino e aprendizagem. $O$ uso da tecnologia alterou não somente as ferramentas de abordagem educacionais, mas o acesso à educação formal por indivíduos que em outra circunstância talvez não tivessem as condições de concretizar seus estudos e este acesso se traduz no ensino à distância.

Porém, na modalidade de ensino a distância, para que tal acesso seja efetivo nos objetivos de aprendizagem, somamos aos desafios tecnológicos outros tantos que se impõem aos docentes e corpo pedagógico para assegurar a qualidade do ensino, formação adequada, e interação teórico-prática dos discentes. Com base nessa perspectiva, este estudo pretende apresentar as estratégias utilizadas pelo curso de graduação no Bacharelado em Serviço Social EAD da UNICESUMAR na formação profissional dos discentes, nas disciplinas que envolvem o estágio curricular obrigatório.

\section{MATERIAIS E MÉTODOS}

O presente artigo irá abordar o estágio supervisionado obrigatório do curso de Bacharelado em Serviço Social EAD, ao que se refere às diferentes disciplinas implantadas na formação para auxiliar na prática profissional, sendo fundamental destacar a abordagem qualitativa, por meio de um estudo descritivo, pautado na análise documental de relatórios institucionais. Nesse sentido, Rocha e Bernardo (2011, p. 88) salientam que: "[...] como o próprio nome aponta, a pesquisa bibliográfica é aquela feita a partir de bibliografia variada, ou seja, engloba livros, revistas, jornais, publicações técnicas, dentre outras fontes escritas."

Entre as abordagens qualitativas, será utilizado o método de revisão narrativa da literatura para a coleta de dados por meio da fundamentação teórica, como também, desenvolver uma discussão e análise para alcançar o objetivo proposto. Compreendem no levantamento da literatura sobre o tema, seleção, fichamento e arquivamento de informações relacionadas à pesquisa. Revisão da literatura é o processo de busca, apreciação crítica, análise e descrição das informações selecionadas de um conjunto do conhecimento em busca de resposta a uma determinada pergunta. A bibliografia engloba um gama de materiais relevantes escrito sobre um tema: livros, artigos de periódicos, artigos de jornais, relatórios governamentais, registros históricos, teses e dissertações e outros tipos. A revisão narrativa não utiliza de métodos explícitos e sistemáticos para a busca e análise crítica da literatura, não esgotando todas as fontes 
de informações. Não aplica estratégias de busca sofisticadas e exaustivas, sendo que a seleção dos estudos e a interpretação das informações podem estar sujeitas à subjetividade dos autores (UNESP, 2015).

\section{CURSO DE BACHARELADO EM SERVIÇO SOCIAL EAD - UNICESUMAR}

A Unicesumar passou a ofertar o curso de Bacharelado em Serviço Social na modalidade Ead no ano de 2014, por meio da Portaria no 23 de 05 de setembro de 2013 (criação do curso Ead). Desde então, o curso está sob a coordenação da professora Me. Maria Cristina Araújo de Brito Cunha, conforme ATA do Núcleo Docente Estruturante do Curso de Bacharelado em Serviço Social - NDE, em 28 de agosto de 2013. O curso segue as diretrizes curriculares conforme preconiza o Ministério de Educação através da Lei № 9.394 de 20 de dezembro de 1996, tem duração de 04 anos (48 meses) com 3.320 horas e 100 horas atividades complementares, teve o curso Reconhecido pelo MEC | Portaria no 1.039, de 03 de outubro de 2017 | Nota 5 (Portal e-MEC ${ }^{\text {[1] }}$ ). Apresentamos a evolução do número de matrículas para o curso, por ano e módulo , com base nos relatorios institucionais:

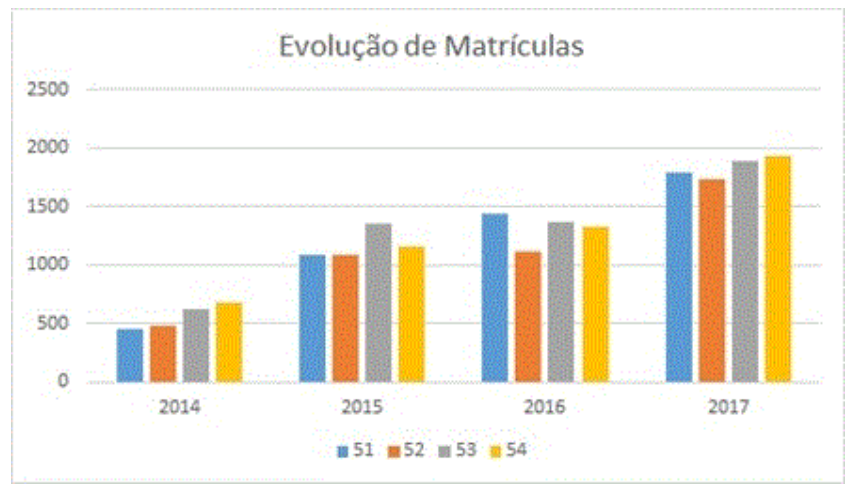

Gráfico1: Evolução no número de matrículas por ano e módulo

O curso é ofertado de forma modular, possibilitando quatro novas turmas durante o ano letivo. Conforme o Projeto Político Pedagógico do curso, que visa o processo de ensinoaprendizagem do acadêmico, a grade curricular foi elaborada com interface entre as disciplinas ofertadas com a realidade social, totalizando 36 disciplinas, o curso oferta a disciplina de Libras como optativa, que são divididas entre comuns e específicas, como estágio curricular obrigatório (que iremos trabalhar nos próximos tópicos) e Trabalho de Conclusão de Curso que deve estar em consonância ao campo de estágio curricular obrigatório.

\subsection{DISCIPLINAS DE ESTÁGIO SUPERVISIONADO OBRIGATÓRIO}


Neste tópico, aborda-se as disciplinas ministradas em Estágio Curricular Obrigatório do curso de Bacharelado em Serviço Social ofertado pela Unicesumar, com base na Lei no 11.788/2008, que em seu art. $1^{\circ}, \S 1^{\circ}$, determina que: "O estágio faz parte do projeto pedagógico do curso, além de integrar o itinerário formativo do educando". Com base nesta prerrogativa, as disciplinas de estágio que compõem o Projeto Político Pedagógico do curso de serviço social da instituição foram organizadas com foco estratégico na qualificação da formação profissional acadêmica, com carga total de 500 horas das disciplinas de estágio e as respectivas ementas são distribuídas da seguinte maneira:

- Estágio Supervisionado: Orientações Didático-Pedagógicas - 100 horas teóricas. Ementa: Os instrumentos legais que normatizam o estágio supervisionado em serviço social. Focaliza o estudo das dimensões teórico metodológica, técnicooperativa e ético-política do fazer profissional do assistente social. Discute a importância da disciplina de estágio supervisionado no processo formativo, realizase orientações quanto à documentação, o papel dos atores envolvidos na supervisão acadêmica e de campo.

- Estágio Supervisionado: Políticas Públicas - 80 horas práticas e 20 teóricas. Ementa: O conhecimento da realidade organizacional no âmbito das políticas públicas de maneira a identificar as demandas dos usuários, bem como as possibilidades profissionais. O exercício de articulação com o conteúdo de outras disciplinas curriculares do curso. A dinâmica institucional e a experimentação prática dos conhecimentos profissionais já construídos.

- Estágio Supervisionado: Observatório Social - 80 horas práticas e 20 teóricas. Ementa: Inter-relação realidade sócio institucional e prática profissional a partir do contexto de observatório social. Domínio de ferramentas de acesso a fontes de pesquisa para análise de indicadores sociais, e sua aplicabilidade na intervenção profissional.

- Estágio Supervisionado: Terceiro Setor e Conselhos Gestores - 80 horas práticas e 20 teóricas. Ementa: Supervisão sistemática no terceiro nível do estágio supervisionado, por meio de aulas teóricas e práticas. Análise crítica do contexto das políticas públicas com ênfase na análise da intervenção profissional no terceiro setor e a participação dos assistentes sociais no âmbito do terceiro setor.

- Estágio Supervisionado: Serviço Social e Empreendedorismo - 80 horas práticas e 20 teóricas. Ementa: Analisar a ação interventiva na realidade institucional. Elaboração e execução de planos de intervenção profissional empreendedora voltado ao atendimento das demandas sociais e suas diversas vertentes de frentes de atuação.(CESUMAR, 2014, p. 42-49).

Desta forma, o estágio supervisionado, além das obrigatoriedades exigidas pelos órgãos 
competentes, possui uma dimensão ético-política, que leva o acadêmico a desenvolver integração com a formação profissional crítica, competente e compromissada, com trocas de experiências, atividades diretamente ligadas ao campo de estágio de forma articulada, coesa, trabalhos em grupos, entre outras que faz com que acadêmico estabeleça uma interação com a realidade do campo, pautando suas decisões profissionais, por meio de um processo sócio-educativo.

\footnotetext{
Estágio Supervisionado é uma atividade curricular obrigatória, que se configura a partir da inserção do aluno no espaço sócio-institucional para capacitação do exercício do Processo de Trabalho do Assistente Social, o que pressupõe supervisão sistemática. Essa supervisão será feita obrigatoriamente pelo professor supervisor através da reflexão, acompanhamento e sistematização com base em planos de estágio elaborado em conjunto entre unidade de ensino e unidade campo de estágio, tendo como referência a Lei de Regulamentação da Profissão e o Código de Ética Profissional (ABESS, 1996.19)
}

A supervisão acadêmica direta e de maneira sistemática-pedagógica, traz aos acadêmicos um processo de ensino-aprendizagem comprometidos estrategiacamente com as Diretrizes Curriculares e o Projeto Político Pedagógico do curso. Sendo este processo acompanhado pelas coordenações de estágio e do curso de Serviço Social Ead Unicesumar, com o intuito de trazer uma reflexão entre a teoria e a prática profissional, valorizando a qualidade dos estágios curriculares ofertados aos acadêmicos em conformidade com a Política Nacional de Estágio (PNE/2010), da Associação Brasileira de Ensino e Pesquisa em Serviço Social (ABEPSS) e nas Resoluções no 533/2008 e 568/2010 do Conselho Federal de Serviço Social (CFESS).

\subsection{METODOLOGIAS DE ENSINO DAS DISCIPLINAS DE ESTÁGIO}

Ao conceber o estágio supervisionado no processo de formação profissional como momento específico/privilegiado, a teoria ilumina a prática e ambas, com suas especificidades, somam-se e configuram-se como unidade, portanto, dependem uma da outra e são importantes para o direcionamento no fazer profissional, no cotidiano do/a assistente social e para que num processo reflexivo possa buscar o desvelamento do real. E que, para Kenski (et al., 2012, p 13): "A teoria dos estilos de aprendizagem contribui muito para a construção do processo de ensino e aprendizagem na perspectiva das tecnologias digitais, porque considera as diferenças individuais e é flexível, o que permite estruturar as atividades de acordo com as especificidades do meio virtual".

Tal unidade se insere na inter-relação das dimensões teórico-metodológica, éticopolíticas e técnico-operativas, vinculado com o projeto ético-político do Serviço Social. Desta forma o acadêmico(a), irá utilizar dos conhecimentos adquiridos ao longo dos conteúdos conceituais trabalhados durante o curso, fazendo uma correlação com a dinâmica da realidade social, que se realiza na perspectiva da práxis. Para que haja esta 
correlação, o curso de Bacharelado em Serviço Social Ead (UNICESUMAR), utiliza-se de metodologias de ensino-aprendizagem diferenciadas, nas disciplinas de estágio curricular, além das atividades obrigatórias, com exceção do Estágio Supervisionado: Orientações Didático-Pedagógicas, que é 100\% teórico, com atividades iguais às outras disciplinas do curso. As demais disciplinas de estágio (citadas anteriormente) possuem uma metodologia diferenciada, com atividades distintas, no entanto, complementares por meio de seus conteúdos. De acordo com MEC (2007): "Apesar da possibilidade de diferentes modos de organização, um ponto deve ser comum a todos aqueles que desenvolvem projetos nessa modalidade: é a compreensão de EDUCAÇÃO como fundamento primeiro, antes de se pensar no modo de organização: A DISTÂNCIA". No curso em análise as atividades e ferramentas disponibilizadas aos acadêmicos(as) durante as disciplinas são planejadas de forma que os leve a desenvolver a criticidade, interpretação e investigação acerca dos conteúdos previstos nas ementas das disciplinas, conforme segue:

Aplicativo APP Studeo: Promove acesso rápido às aulas e materiais, possui opção exclusiva de notificações para avisos pedagógicos, lembretes de atividades e provas.

Aulas ao vivo: Momento de aproximação e interação entre o docente, mediador e os alunos que estão cursando a disciplina de estágio, sendo destinado ao docente o papel de estabelecer a relação entre os conteúdos teóricos e experiências vivenciadas no campo de estágio que são relatas pelos acadêmicos.

Aulas conceituais: Aulas gravadas pelos professores formadores ou conteudistas, com base no material didático que possibilitam ao acadêmico compreender os conceitos relacionados ao conteúdo da disciplina. Ficam disponíveis para download posterior.

Estudo de caso: Filme de 50 minutos preparado e desenvolvido pelo docente da disciplina, apresentando uma situação-problema fictícia, casos reais, entrevistas relevantes. Promove a aproximação entre teoria e prática, efetivando a correlação da fundamentação teórica discutida e as atividades práticas de estágio.

Atividade de estudo: Atividade avaliativa online, desenvolvida a partir de textos complementares escritos pelo professor, ou pautada em livros disponibilizados na biblioteca virtual. Composta por dez questões objetivas de diferentes níveis de complexidade que promovem ao acadêmico a reflexão, pesquisa, interpretação e análise de situações correlatas a prática profissional e conhecimentos indispensáveis para a formação profissional. 
Material de Avaliação Prática de Aprendizagem (M.A.P.A): Atividade final que objetiva a sistematização do processo conhecimento proposto em cada disciplina, (aulas + aulas conceituais + estudo de caso + atividade de estudo + campo de estágio). O acadêmico(a) matriculado na disciplina de estágio deve desenvolver um paper/artigo a partir de levantamento de dados e posteriormente sistematizá-lo de forma científica, estimulando a escrita e análise crítica.

Biblioteca virtual: Ferramenta de apoio para os acadêmicos (as), com o incentivo à pesquisa de conteúdos extra sala de aula, para realização de atividades. Os arquivos ficam disponíveis para download e consultas conforme a necessidade do acadêmico, para maior flexibilidade nos estudos.

Mini tutoriais: Pequenos vídeos elaborados e gravados pelos professores formadores e tutores a fim de esclarecer dúvidas relacionadas às atividades e conteúdos. Estes ficam disponíveis no ambiente do acadêmico (a) para tirarem suas dúvidas sempre que necessário.

Material Extra: Oportuniza ao acadêmico a ampliação de seu conhecimento, acerca dos conteúdos da disciplina, assuntos relacionados ao campo de estágio, atuação profissional, itens que possam contribuir para a formação.

As estratégias de aproximação com o aluno são sempre voltadas para a inovação em suas metodologias e ferramentas, para que o melhor resultado educacional possa ser obtido. Estas estratégias se efetivam por meio da habilidade e capacitação dos atores envolvidos no processo de formação, sendo estes, a coordenação de estágio, professores, mediadores, tutores e os supervisores acadêmicos, como uma rede.

\subsubsection{CAPACITAÇÃO DOS SUPERVISORES ACADÊMICOS DE SERVIÇO SOCIAL}

Os Polos de apoio presencial, no momento da contratação de supervisores acadêmicos, devem respeitar o processo interno nº 198: Estágio Supervisionado em Serviço Social, onde constam todas as orientações primárias sobre a função, tais como objetivos, descrição do processo, documentações, plano de trabalho do supervisor, entre outros. (CESUMAR, 2014).

A importância da discussão da supervisão de estágio, entendida como um espaço que deve tanto garantir como viabilizar o processo de ensino-aprendizagem, é possibilitar a reflexão e o questionamento crítico. Tem, portanto, uma dimensão pedagógica por excelência. Tanto o aluno quanto o supervisor devem estar integralmente comprometidos com esse processo. (COSTA; CUNHA, 2016, p.17). 
Verificamos que para acompanhar os acadêmicos, os supervisores precisam estar alinhados com a metodologia do curso, o Projeto Político Pedagógico, bem como as diretrizes de estágio. Identificamos assim que em conjunto, a Coordenação do Curso e coordenação de estágio, desenvolveram um projeto de capacitação online para os supervisores acadêmicos, onde todos estão conectados ao mesmo tempo, tendo o mesmo direcionamento, qualificação e aprimoramento. Os supervisores acadêmicos que por algum motivo não podem participar das capacitações e reuniões ao vivo, podem fazê-la por demanda, ou seja, a capacitação ao vivo é gravada e disponibilizada posteriormente no ambiente virtual dos supervisores acadêmicos.

Há uma necessidade urgente de inovação estratégicas para assegurar a formação com qualidade, e no que se refere à atualização didática digital dos docentes e atores no processo deve ter foco prioritário (KENSKI, 2015). Por este fato, as capacitações são ao vivo com chat de perguntas para serem respondidas, desta forma tirando as dúvidas em tempo real, posteriormente ficam disponíveis sob demanda, dentro do ambiente virtual Studeo. Ressalta-se que o ambiente virtual os supervisores acadêmicos têm acesso é o mesmo dos alunos, este ambiente é personalizado para os supervisores, de acordo com a necessidade prevista. Ou seja, o supervisor pode assistir as capacitações e reuniões, tem acesso ao material extra (que consiste em todos os documentos obrigatórios para estágio, legislações, textos para estudo, etc) ; fórum de debates e informações; sala do café. Para que o processo de supervisão seja contextualizado, os supervisores acadêmicos ainda têm acesso a todas as aulas ao vivo das disciplinas de estágio, e assim podem acompanhar as discussões e inclusive, podem contribuir com as mesmas durante as aulas, proporcionando uma discussão ampliada acerca dos conteúdos.

\footnotetext{
Assim, o processo de formação profissional e, particularmente o estágio supervisionado curricular, devem garantir a apreensão do significado sócio histórico do Serviço Social; das condições de trabalho dos assistentes sociais; das conjunturas; das instituições; do universo dos trabalhadores usuários dos diversos serviços e das políticas sociais. Neste aspecto, exige conhecimentos teóricos e saberes prático-interventivos, além, é claro, dos fundamentos e da lógica tendencial que os constituem (GUERRA, 2006, p. 32).
}

Percebe-se que estes acompanhamentos realizados aos supervisores, traz para os acadêmicos um profissional capacitado ao atendimento individual, que considera as reflexões teórico-metodológicas, o desempenho ético-político (profissional) e os fatores com as facilidade e dificuldades da prática profissional. Destaca-se que para que esta articulação seja efetiva, deve haver um desenvolvimento por todos e não somente delegado a responsabilidade ao único sujeito.

\section{CONSIDERAÇÕES FINAIS}


O presente estudo teve como principal objetivo apresentar as principais características do estágio curricular obrigatório do curso de Bacharelado em Serviço Social na modalidade Ead da UNICESUMAR. Depreende-se que este processo é contínuo, planejado e avaliado continuamente, buscando proporcionar um processo de qualidade no ensino-aprendizagem, preparando os acadêmicos para o mercado de trabalho, com formação profissional que rompe com paradigmas no que se refere a Práxis. O grande desafio no curso de Bacharelado em Serviço Social ofertado pela Unicesumar são os conteúdos abordados durante o Estágio Curricular Obrigatório, que buscam abordar a práxis profissional, sempre pautando-se nas normativas profissionais. Colocar-se no lugar do aluno e compreender como ele aprende, quais suas dúvidas, onde ele quer chegar faz com que professores busquem, de maneiras mais criativas, contribuir para a criação do conhecimento em sala de aula, criando pontes entre os conteúdos estudados, fazendo com que o aluno seja 0 autor do seu próprio aprendizado, construindo seu conhecimento.

Conforme analisado anteriormente a supervisão acadêmica desempenha um papel de fundamental importância no processo de ensino-aprendizagem. Para tanto as capacitações realizadas e as tecnologias empregadas nessa modalidade de educação, colaboram de forma que os acadêmicos tenham um profissional preparado para desenvolver seus papéis no processo educativo. Independente da modalidade de ensino e metodologia empregada, prima-se sempre pela qualidade. Para tanto, o ensino a distância tem estabelecido estratégias por meio das tecnologias, para encurtar a distância entre o supervisor acadêmico e as coordenações de estágio e de curso, para que todos os aspectos legais do estágio curricular obrigatório exigidos pelo MEC e Conselhos da categoria profissional sejam cumpridos. Compreende-se que não existe um modelo único para a Educação a Distância - EAD no Brasil. São diversos modelos, cada qual com sua característica, porém, com objetivo único de levar educação com excelência ao acadêmico(a), independente onde esteja.

\section{REFERÊNCIAS}

ABEPSS. Diretrizes Gerais para o curso de Serviço Social. Rio de Janeiro, 1996.

BRASIL. Lei o 11.788 de 25 de setembro de 2008. Dispõe sobre os estágios de estudantes.

CENTRO UNIVERSITÁRIO DE MARINGÁ. Núcleo de Educação a Distância. ATA DO NÚCLEO DOCENTE ESTRUTURANTE DO CURSO DE BACHARELADO EM SERVIÇO SOCIAL. Maringá: CESUMAR, 2013. 
CENTRO UNIVERSITÁRIO DE MARINGÁ. Núcleo de Educação a Distância. Projeto Político Pedagógico do Curso de Bacharelado em Serviço Social. Maringá: UNICESUMAR,2014.

CENTRO UNIVERSITÁRIO DE MARINGÁ. Departamento de Processos e Qualidade Núcleo de Educação a Distância. Processo no 198 Estágio Supervisionado em Serviço Social. Maringá: UNICESUMAR,2014.

COSTA, Valéria Cristina; CUNHA, Maria Cristina Araújo de Brito. Manual de Estágio do Curso Serviço Social. Maringá: UNICESUMAR,2016.

GUERRA, Y. Análise dos Dados da Pesquisa sobre o Estado da Arte da Implementação das Novas Diretrizes Curriculares. Oficina descentralizada de ABEPSS "10 Anos de diretrizes curriculares - um balanço necessário". Minas Gerais: UFJF, Universidade Federal de Juiz de Fora, 2006. Texto mimeo.

KENSKI, V. M. A urgência de propostas inovadoras para a formação de professores para todos os níveis de ensino. Rev. Diálogo Educ., Curitiba, v.15, n. 45, p.423-441, mai/ago. 2015.2 Disponível em: <https://periodicos.pucpr.br/index.php/dialogoeducacional/article/view/1963>. Acessoem 20, jul, 2018.

KENSKI, V. M.; BARROS, D, M. V.; OKADA, A. Coletividade aberta de pesquisa: os estilos de coaprendizagem no cenário online. Rev. Educom. Educação, formação \& tecnologias, $\quad 2012 . \quad$ Dortugal. <https://repositorioaberto.uab.pt/bitstream/10400.2/3000/1/313-1647-1-PB\%20(1).pdf>. Acesso em: 20, jul, 2018.

UNESP. Tipos de revisão da literatura. Botucatu: Biblioteca Prof. paulo de carvalho Mattos. $\quad 2015 . \quad$ Disponível em: $<$ http://www.fca.unesp.br/Home/Biblioteca/tipos-de-evisao-de-literatura.pdf $>$. Acesso em: 08 Ago. 2018.

MEC. Referenciais de qualidade para educação superior a distância. Brasília, 2007. Disponível em: <http://portal.mec.gov.br/seed/arquivos/pdf/legislacao/refead1.pdf>. Acesso em: 17 mai 2018.

ROCHA, A. S.; BERNARDO, D. G. Pesquisa bibliográfica: entre conceitos e fazeres. Maringá: Eduem, p. 81-100, 2011. 